http://dx.doi.org/10.32929/2446-8355.2019v28n1p19-28

\title{
TESTE DE PATOGENICIDADE DOS ISOLADOS DE Pyricularia oryzae NOS HOSPEDEIROS DE TRIGO, CEVADA, ARROZ E BRAQUIÁRIA
}

Juliana Teodora de Assis Reges ${ }^{1 *}$, Michelle Nogueira de Jesus ${ }^{2}$, Simone Duarte Ramalho da Silva $^{2}$, Marcelo Henrique de Souza ${ }^{2}$, Josiane Walleria Rodrigues ${ }^{2}$

\footnotetext{
${ }^{1}$ Dra. Engenheira Agrônoma, Docente da Universidade Estadual de Goiás - Campus de Jataí (GO). *E-mail do autor correspondente: juliana.teodora@bol.com.br

${ }^{2}$ Discente do curso de Tecnologia de Alimentos da Universidade Estadual de Goiás - Campus de Jataí (GO).
}

Recebido: 24/01/2018; Aceito: 14/03/2019

RESUMO: A Espécies de fungos do gênero Pyricularia estão associadas com a doença brusone em plantas da família Poaceae. Pyricularia oryzae é a espécie de maior incidência e distribuição mundial, causando perdas em culturas de importância econômica como arroz, aveia, centeio, cevada, trigo e triticale. Dessa forma, este estudo teve como objetivo caracterizar o espectro de patogenicidade de $P$. oryzae do trigo e plantas invasoras nos hospedeiros de trigo, braquiária, arroz e cevada. A pesquisa foi conduzida no Laboratório e na casa-de-vegetação na Universidade Estadual de Goiás, no Campus de Jataí. Foram testados 28 isolados de $P$. oryzae obtidos de amostras de folhas infectadas de plantas invasoras de campos de trigo e dois isolados de $P$. oryzae foram obtidos da espiga do arroz. De acordo com os resultados, conclui-se que os isolados de $P$. oryzae testados, foram patogênicas à trigo, cevada, arroz e braquiária, com diferenças na agressividade.

Palavras-chave: Brusone. Triticum aestivum. Inoculação. Agressividade.

\section{PATHOGENICITY TEST OF THE ISOLATES OF Pyricularia oryzae IN THE HOSTS OF WHEAT, BARLEY, RICE AND BRAQUIARIA}

\begin{abstract}
A Species of fungi of the genus Pyricularia are associated with the blight disease in plants of the family Poaceae. Pyricularia oryzae is the species with the highest incidence and distribution worldwide, causing losses in crops of economic importance such as rice, oats, barley, wheat and triticale. Thus, this study aimed to characterize the pathogenicity spectrum of $P$. oryzae of wheat and invasive plants in wheat, brachiaria, rice and barley hosts. The research was conducted in the Laboratory and in the greenhouse at the State University of Goiás, at Campus de Jataí. Twenty-eight isolates of Pyricularia oryzae obtained from infected leaf samples of wheat field invasive plants were tested and two isolates of Pyricularia oryzae were obtained from the ear of rice. According to the results, it was concluded that the isolates of Pyricularia oryzae tested were pathogenic to wheat, barley, rice and brachiaria, with differences in aggressiveness.
\end{abstract}

Key words: Brusone. Triticum aestivum. Inoculation. Aggressiveness. 


\section{INTRODUÇÃO}

Os primeiros surtos da brusone do trigo no Brasil, com prejuízos significativos à produção, ocorrem no ano de 1986, nas regiões Norte e Oeste do Paraná (PR), assim como Noroeste de São Paulo e Sul do Mato Grosso do Sul. (IGARASHI et al., 1986; IGARASHI, 1988). Em folhas de trigo, as lesões têm forma elíptica e alongada, acompanhando as nervuras, com dimensões de 1-2 por 21-25 mm, com coloração central que varia de branco a castanho claro e as bordas castanho-avermelhado. O tamanho e a intensidade de descoloração da lesão variam com a idade da planta (IGARASHI, 1988). Em plantas jovens de trigo os sintomas foliares da brusone são semelhantes aos observados em outros hospedeiros, como em cevada e braquiária (REGES et al., 2016). A predominância de sintomas em espigas e a rara incidência da brusone nas folhas do trigo leva à hipótese de que o inóculo primário do patógeno provém de lesões em outros hospedeiros (DUVEILLER et al., 2010), especialmente em espécies de poáceas cultivadas em larga escala como pastagens dos gêneros Urochloa (braquiária) e Panicum (REGES et al., 2016).

O gênero Pyricularia é composto por diversas espécies de fungos fitopatogênicos que estão associados com a brusone em mais de 50 espécies de plantas poáceas (OU, 1985). Entre as espécies desse gênero, Pyricularia oryzae é possivelmente o patógeno mais importante em função de sua distribuição cosmopolita em plantas poáceas. A brusone ocasionada por $P$. oryzae é responsável por perdas severas, sob condições predisponentes, em culturas de importância econômica como arroz (Oryza sativa), aveia (Avena sativa), capim-braquiária (Urochloa spp.), centeio (Secale cereale), cevada (Hordeum vulgare), milho (Zea mays) e trigo (Triticum aestivum) (ANJOS et al., 1996; BAILEY e EIJNATTEN, 1961; COUCH et al., 2005; COUCH e KOHN 2002; IGARASHI et al., 1986; GOULART et al., 2003; MARCHI et al., 2005; URASHIMA et al., 1993; REGES et al., 2016; REGES, 2016).

Devido à falta de cultivares com altos níveis de resistência genética e de controle químico eficaz para o manejo da brusone, o patógeno tornou-se amplamente distribuído em todas as áreas de cultivo de trigo no Brasil (CASTROAGUDÍN et al., 2015; MACIEL et al., 2014). Diante dessa problemática o principal objetivo deste trabalho foi caracterizar o espectro de patogenicidade de P.oryzae do trigo e plantas invasoras nos hospedeiros de trigo, braquiária, arroz e cevada.

\section{MATERIAL E MÉTODOS}

\section{Amostragem das Plantas}

Foram amostradas em uma lavoura de trigo, populações simpátricas (das mesmas áreas) as espiga de trigo e folhas de plantas invasoras com sintomas de brusone na Região de Rio Verde- GO. As populações de $P$. oryzae que infectam o trigo foram obtidas por amostragem de transectos. Já a amostragem de Poaceas invasoras foi tomada em um raio às margens do campo de trigo. A coleta das invasoras foi efetuada em locais que não excederam $100 \mathrm{~m}$ da lavoura de trigo de referência. As plantas encontradas foram colocadas em sacos de papel, secas ao ar e mantidas à $-20^{\circ} \mathrm{C}$ até o momento do isolamento. 


\section{Isolamento}

Os isolamentos foram conduzidos na Universidade Estadual de Goiás (UEG), Campus Jataí, localizado no município de Jataí-GO. Os Isolamentos de $P$. oryzae de espigas de trigo e de outras plantas Poáceas invasoras infectadas foram processados nos anos de 2016 e 2017. Os isolamentos dos patógenos foram seguidos os procedimentos descrito por Cruz et al., (2010). De cada amostra infectada foi retirada apenas um isolado monospórico. Para a obtenção de isolados monospóricos foram utilizadas folhas, ráquis e glumas de plantas de trigo ou folhas de plantas invasoras com sintomas de brusone. Realizou-se a assepsia do material, que permaneceu em câmara úmida por $24 \mathrm{~h}$. Em seguida, com o auxílio de uma lupa procedeu-se ao isolamento dos conídios de $P$. oryzae. Os conídios foram transferidos, primeiramente, para o meio ágar-água e, após $15 \mathrm{~h}$, apenas os conídios germinados foram transferidos para o meio aveia-ágar até o desenvolvimento das colônias. Os isolados de $P$. oryzae foram preservados pela técnica do papel de filtro, mantidos em sílica-gel à $-20^{\circ} \mathrm{C}$.

\section{Origem dos isolados}

Para o estudo comparativo da caracterização fenotípica de isolados de $P$. oryzae, foram utilizados 28 isolados provenientes de folhas de plantas invasoras ou espigas de trigo é dois isolados de arroz, de acordo com a Tabela 1.

Tabela 1. Isolados de Pyricularia oryzae obtidos de amostras de trigo e gramíneas invasoras de áreas de trigo em 2016 e 2017. Isolates of Pyricularia oryzae obtained from wheat and invasive grass samples from wheat areas in 2016 and 2017.

\begin{tabular}{lll}
\hline Isolado & Nome Comum do Hospedeiro & Hospedeiro \\
$16.0 .001 \mathrm{j}$ & Capim-braquiária & Urochloa spp. \\
$16.0 .002 \mathrm{j}$ & Capim-colonião & Panicum maximum \\
$16.0 .003 \mathrm{j}$ & Capim-braquiária & Urochloa spp. \\
$16.0 .004 \mathrm{j}$ & Capim-braquiária & Urochloa spp. \\
$16.0 .005 \mathrm{j}$ & Capim-carrapixo & Cenchrus echinatus \\
$16.0 .006 \mathrm{j}$ & Capim-braquiária & Urochloa spp. \\
$16.0 .007 \mathrm{j}$ & Capim-carrapixo & Cenchrus echinatus \\
$16.0 .008 \mathrm{j}$ & Capim-carrapixo & Cenchrus echinatus \\
$16.0 .009 \mathrm{j}$ & Capim-braquiária & Urochloa spp. \\
$16.0 .010 \mathrm{j}$ & Capim-colonião & Panicum maximum \\
$16.0 .011 \mathrm{j}$ & Capim-braquiária & Urochloa spp. \\
$16.0 .012 \mathrm{j}$ & Capim-colonião & Panicum maximum \\
$16.0 .013 \mathrm{j}$ & Capim-braquiária & Urochloa spp.. \\
$16.1 .001 \mathrm{j}$ & Trigo & Triticum aestivum \\
$16.1 .002 \mathrm{j}$ & Trigo & Triticum aestivum \\
$16.1 .003 \mathrm{j}$ & Trigo & Triticum aestivum \\
$16.1 .004 \mathrm{j}$ & Trigo & Triticum aestivum \\
$16.1 .005 \mathrm{j}$ & Trigo & Triticum aestivum \\
$16.1 .006 \mathrm{j}$ & Trigo & Triticum aestivum \\
$16.1 .007 \mathrm{j}$ & Trigo & Triticum aestivum \\
\hline
\end{tabular}


Tabela 1. Continuação...

\begin{tabular}{lll}
\hline Isolado & Nome Comum do Hospedeiro & Hospedeiro \\
$16.1 .008 \mathrm{j}$ & Trigo & Triticum aestivum \\
$16.1 .009 \mathrm{j}$ & Trigo & Triticum aestivum \\
$16.1 .010 \mathrm{j}$ & Trigo & Triticum aestivum \\
$16.1 .011 \mathrm{j}$ & Trigo & Triticum aestivum \\
$16.1 .012 \mathrm{j}$ & Trigo & Triticum aestivum \\
$16.1 .013 \mathrm{j}$ & Trigo & Triticum aestivum \\
$16.1 .014 \mathrm{j}$ & Trigo & Triticum aestivum \\
$16.1 .015 \mathrm{j}$ & Trigo & Triticum aestivum \\
001 & Arroz & Oryza sativa \\
002 & Arroz & Oryza sativa \\
\hline
\end{tabular}

\section{Preparo do inóculo}

Os isolados de P.oryzae foram cultivados em placas de Petri contendo meio aveia-ágar e mantidos sob fotoperíodo de 12 horas e temperatura de $25{ }^{\circ} \mathrm{C}$, durante cinco dias. Foram transferidos discos de $5 \mathrm{~mm}$ contendo micélio e conídios de Pyricularia spp. para 10 placas contendo meio de aveia, para produção e obtenção de esporos. As colônias de fungos foram mantidas por 15 dias sob as mesmas condições de cultivo (MACIEL et al., 2014; REGES, 2016).

Para a preparação do inóculo, o micélio foi raspado com o auxílio de uma espátula esterilizada e colônias fúngicas lavadas com água destilada acrescida de espalhante adesivo Tween 80 ( 2 gotas $\left.\mathrm{L}^{-1}\right)$. A concentração de conídios em suspensão foi determinada em uma câmara de Neubauer, ajustando-se para $10^{5}$ conídios $\mathrm{mL}^{-1}$ para a inoculação (MACIEL et al., 2014; REGES, 2016). O volume de suspensão de conídios para inoculação em plantas jovens foi de $50 \mathrm{~mL}$ para um total de 5 vasos.

\section{Semeadura}

As semeaduras dos hospedeiros de trigo (T. aestivum) cv. BRS 264, braquiária (Urochloa brizantha) cv. Piatã, cevada (Hordeum vulgare) cv. BRS Korbel e do arroz $(O-$ sativa) cv IRGA 409, foram realizadas no dia 6 de setembro de 2016 e no dia 4 de maio de 2017, o experimento foi conduzido em duas vezes. Cerca de 8 a 10 sementes foram semeadas em saquinhos plásticos de $300 \mathrm{~mL}$, contendo substrato para plantas Tropstrato HT hortaliças (Vida Verde). As plantas foram mantidas em telado à temperatura de 25 a $30{ }^{\circ} \mathrm{C}$ e regime de 12 horas de luz, e foram irrigadas diariamente. Uma adubação (4,0 g/vaso) com o formulado N-P-K (10-10-10) foi realizada 10 dias após as semeaduras.

Três semanas após a emergência quando as plantas testadas estavam no estádio fenológico de quatro folhas, o desbaste foi realizado deixando apenas seis plantas por saquinho. Os saquinhos foram distribuídos aleatoriamente dentro da casa de vegetação seguindo o delineamento casualizado, com 4 cultivares, 5 repetições de cada isolado. Cada parcela experimental consistiu de um vaso contendo seis plantas, totalizando 30 plantas por hospedeiro. 


\section{Inoculação}

A inoculação foi realizada com o auxílio de bomba spray de ar sob pressão. A suspensão de conídios foi pulverizada sobre cada uma das plantas até o total molhamento da superfície foliar, adaxial e abaxial. Após a inoculação, as plantas foram incubadas por 24 horas no escuro em câmara tipo Fitotron, à temperatura de $24{ }^{\circ} \mathrm{C}$ sob nebulização. Após, as parcelas experimentais foram transferidas para casa de vegetação climatizada com controle automático de temperatura do ar $\left(25^{\circ} \mathrm{C}\right)$ e umidade relativa do ar $(90 \%)$, com 12 horas de luz solar, realizando a irrigação dos vasos diariamente.

\section{Avaliação}

As plantas foram avaliadas sete dias após a inoculação. Cinco folhas com sintomas de brusone por vaso foram fotografadas usando uma câmera digital marca Samsung. Os níveis de agressividade dos isolados foram determinados com base na porcentagem de área foliar infectada das plantas com sintomas de brusone. A área foliar infectada foi determinada com o uso do software para análise de imagens digitais Assess Image Analysis Software for Plant Disease Quantification version 2.0 da APS - American Phytopathological Society (Lamari, Department of Plant Science, University of Manitoba, Winnipeg, Manitoba, Canadá).

O delineamento experimental adotado para as espécies hospedeiras foram $\mathrm{o}$ inteiramente casualizado, com cinco repetições. Para cada planta hospedeira, os tratamentos experimentais foram representados por 30 isolados. A análise de variância foi realizada usando o pacote de software os dados foram analisados mediante o procedimento "Assistat" e as médias comparadas pelo teste de Scott-Knott, a 1\% probabilidade (SILVA; AZEVEDO, 2016).

\section{RESULTADOS E DISCUSSÃO}

Diferenças significativas foram detectadas entre a espécie de Pyricularia oryzae quanto à severidade de brusone em trigo, cevada, arroz e braquiária (Tabela 2). Alguns dos isolados de Pyricularia oryzae testadas foram patogênicas à trigo, com exceções aos isolados de arroz. Com relação aos isolados de $P$. oryzae provenientes de plantas invasoras os isolados $16.1 .011 \mathrm{j}$ e 16.0.013j foram o mais agressivo às plantas jovens (Figura 1A), com uma área foliar infectada de 49,61 e 49,89\% respectivamente. Já os grupos de isolados de $P$. oryzae advindos de plantas de trigo, os isolados mais agressivos foram 16.1.001j, 16.1.004j e 16.1.009j, proporcionaram médias de severidade de 49,66, 49, 68 e 49,74\% de área foliar infectada, respectivamente. Os isolados 001 e 002 que foram isolados da espiga de arroz não foram patogênicas ao trigo cv. BRS 264. O resultado já era esperado pois, o trigo tem a presença funcional do gene de avirulência Avr1-CO39 no fungo $P$. oryzae potencialmente impede a infecção de arroz, pois este carrega o gene de resistência Pi-CO39(t) (COUCH et al., 2005). 
Tabela 2. Médias de agressividade dos patógenos de Pyricularia oryzae em hospedeiros de trigo, arroz, cevada e braquiária. Aggression means of Pyricularia oryzae pathogens in wheat, rice, barley and brachiaria hosts.

\begin{tabular}{|c|c|c|c|c|}
\hline Isolados & Trigo & Cevada & Arroz & Braquiária \\
\hline $16.0 .001 \mathrm{j}$ & $30,84 \mathrm{e}$ & $45,88 \mathrm{~d}$ & $45,88 \mathrm{a}$ & $37,87 \mathrm{~d}$ \\
\hline $16.0 .002 \mathrm{j}$ & $18,93 \mathrm{i}$ & $27,48 \mathrm{~h}$ & $27,48 \mathrm{f}$ & 17,481 \\
\hline $16.0 .003 \mathrm{j}$ & $47,35 \mathrm{~b}$ & $26,34 \mathrm{i}$ & 45,89 a & $47,67 \mathrm{a}$ \\
\hline $16.0 .004 j$ & $32,87 \mathrm{e}$ & $35,49 \mathrm{f}$ & $45,90 \mathrm{a}$ & $39,19 \mathrm{c}$ \\
\hline $16.0 .005 \mathrm{j}$ & $46,45 \mathrm{c}$ & $48,55 \mathrm{~b}$ & $28,05 \mathrm{e}$ & $33,78 \mathrm{e}$ \\
\hline $16.0 .006 \mathrm{j}$ & $13,32 \mathrm{j}$ & $21,06 j$ & $21,06 \mathrm{~g}$ & $30,86 \mathrm{f}$ \\
\hline $16.0 .007 \mathrm{j}$ & $18,94 i$ & 19,531 & $19,55 \mathrm{~g}$ & $19,64 j$ \\
\hline $16.0 .008 \mathrm{j}$ & $46,85 \mathrm{c}$ & $44,98 \mathrm{e}$ & $29,87 \mathrm{~d}$ & $21,98 \mathrm{i}$ \\
\hline $16.0 .009 j$ & $22,94 \mathrm{~g}$ & 55,59 a & $38,76 \mathrm{c}$ & $31,65 \mathrm{f}$ \\
\hline $16.0 .010 \mathrm{j}$ & $27,54 \mathrm{f}$ & $26,33 \mathrm{i}$ & $11,95 \mathrm{j}$ & $39,87 \mathrm{c}$ \\
\hline $16.0 .011 j$ & $49,61 \mathrm{a}$ & 55,59 a & $45,91 \mathrm{a}$ & $47,69 a$ \\
\hline $16.0 .012 \mathrm{j}$ & $11,45 \mathrm{j}$ & 19,551 & $17,98 \mathrm{~h}$ & $29,01 \mathrm{~g}$ \\
\hline $16.0 .013 j$ & 49,89 a & 18,811 & $12,86 \mathrm{i}$ & $47,68 \mathrm{a}$ \\
\hline $16.1 .001 j$ & $49,66 \mathrm{a}$ & 18,791 & 1,561 & $18,66 \mathrm{j}$ \\
\hline $16.1 .002 \mathrm{j}$ & $27,19 \mathrm{f}$ & 55,60 a & $0,57 \mathrm{~m}$ & $24,76 \mathrm{~h}$ \\
\hline $16.1 .003 \mathrm{j}$ & $19,29 \mathrm{i}$ & 55,61 a & $0,21 \mathrm{n}$ & $47,68 \mathrm{a}$ \\
\hline $16.1 .004 j$ & $49,68 \mathrm{a}$ & $11,67 \mathrm{n}$ & $0,28 \mathrm{n}$ & $11,69 n$ \\
\hline $16.1 .005 \mathrm{j}$ & $31,89 \mathrm{e}$ & $12,12 \mathrm{~m}$ & $0,12 \mathrm{n}$ & $23,66 \mathrm{~h}$ \\
\hline $16.1 .006 \mathrm{j}$ & $46,78 \mathrm{c}$ & $35,08 \mathrm{f}$ & $0,08 \mathrm{n}$ & $21,98 \mathrm{i}$ \\
\hline $16.1 .007 \mathrm{j}$ & $18,86 \mathrm{i}$ & $35,67 \mathrm{f}$ & $0,22 \mathrm{n}$ & $36,66 \mathrm{~d}$ \\
\hline $16.1 .008 \mathrm{j}$ & $31,78 \mathrm{e}$ & 55,60 a & $0,11 \mathrm{n}$ & $11,36 \mathrm{n}$ \\
\hline 16.1.009j & $49,74 \mathbf{a}$ & $48,21 \mathrm{c}$ & $0,02 \mathrm{n}$ & 47,69 a \\
\hline $16.1 .010 \mathrm{j}$ & $22,08 \mathrm{~h}$ & $11,58 \mathrm{n}$ & $0,04 \mathrm{n}$ & $31,09 \mathrm{f}$ \\
\hline $16.1 .011 \mathrm{j}$ & $17,41 \mathrm{i}$ & $11,61 \mathrm{n}$ & $0,05 \mathrm{n}$ & 47,67 a \\
\hline $16.1 .012 \mathrm{j}$ & $41,98 \mathrm{~d}$ & $26,45 \mathrm{i}$ & $0,11 \mathrm{n}$ & $25,85 \mathrm{~h}$ \\
\hline $16.1 .013 \mathrm{j}$ & $29,61 \mathrm{f}$ & $44,79 \mathrm{e}$ & $0,03 \mathrm{n}$ & $47,62 \mathrm{~b}$ \\
\hline $16.1 .014 \mathrm{j}$ & $17,45 \mathrm{i}$ & $44,81 \mathrm{e}$ & $0,03 \mathrm{n}$ & $39,52 \mathrm{c}$ \\
\hline $16.1 .015 \mathrm{j}$ & $41,98 \mathrm{~d}$ & 55,61 a & $0,02 \mathrm{n}$ & 47,69 a \\
\hline 001 & $0,13 \mathrm{~m}$ & $33,89 \mathrm{f}$ & 45,89 a & $13,46 \mathrm{~m}$ \\
\hline 002 & 0,361 & $31,67 \mathrm{~g}$ & $42,67 \mathrm{~b}$ & $11,67 \mathrm{n}$ \\
\hline $\mathrm{F}$ & $267968,11 * *$ & $7999396,95 * *$ & $5890533,81 * *$ & $5145961,37 * *$ \\
\hline $\mathrm{CV}(\%)$ & 0,14 & 0,04 & 0,07 & 0,03 \\
\hline
\end{tabular}

Médias na coluna seguidas pela mesma letra não diferem entre si, a $1 \%$ de probabilidade pelo teste de ScottKnott. Mean values in the column followed by the same letter do not differ, at $1 \%$ probability by the Scott-Knott test.

Todos os isolados de Pyricularia spp. testados foram patogênicas à cevada cv. BRS Korbel (Tabela 2, Figuras 1B). Portanto os isolados 16.0.009j, 16.0.011j, 16.1.002j, 16.1 003j, $16.1008 \mathrm{j}$ e $16.1 .015 \mathrm{j}$ foram os mais agressivos, com as médias de 55,59; 55,59; 55,60; 55,61; 55,60 e $55,61 \%$ da área foliar infectada, respectivamente. De fato, inúmeras cultivares de cevada têm sido consideradas suscetíveis aos patógenos do gênero Pyricularia, especialmente a espécie de $P$. oryzae (MARANGONI et al., 2013). Há, entretanto, uma variação quanto à resistência à brusone e genótipos com níveis elevados de resistência a $P$. oryzae em relação ao hospedeiro de cevada. (MARANGONI et al., 2013). 


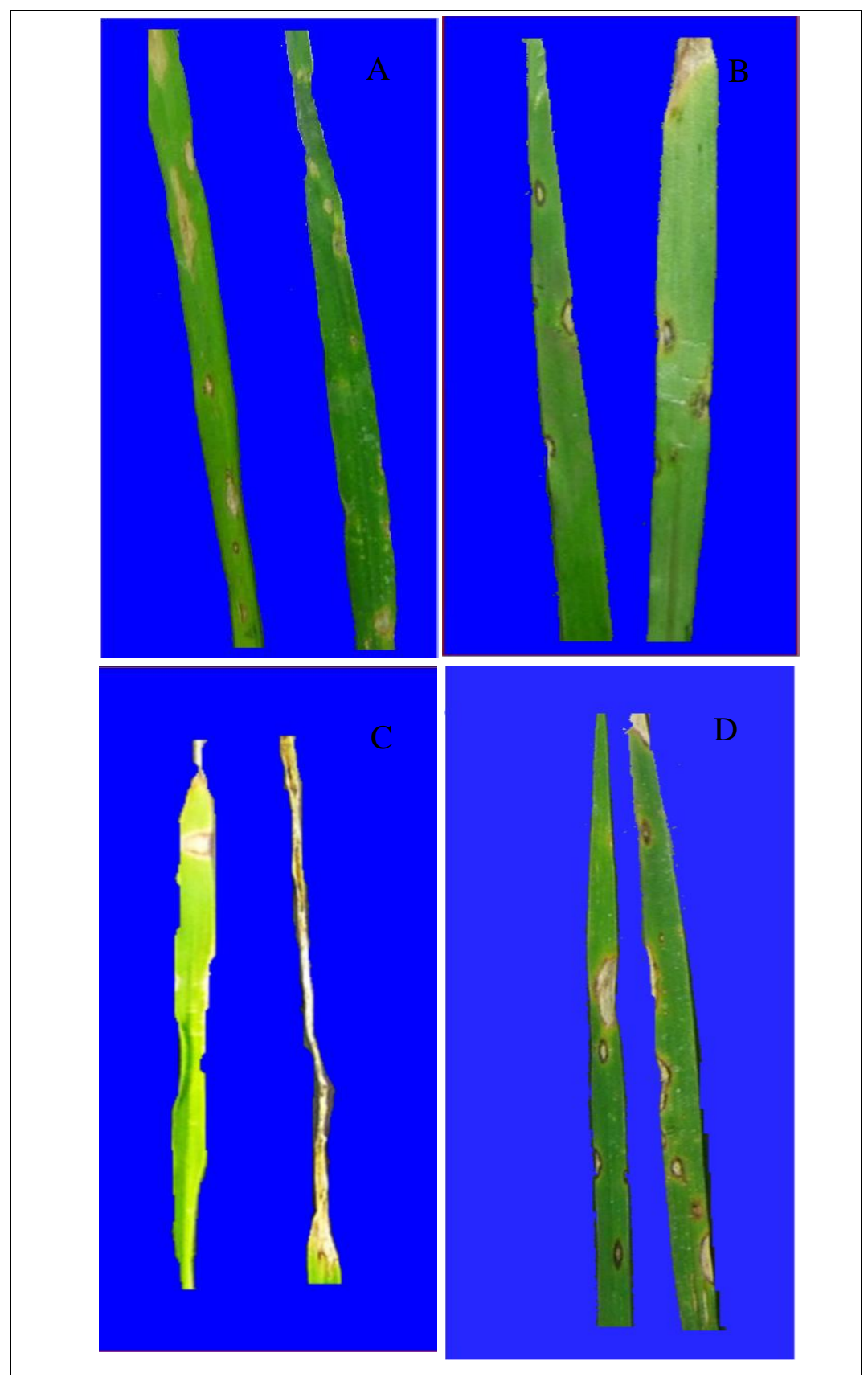

Figura 1. Sintomas de brusone causado pela espécie de Pyricularia oryzae em folhas de trigo cv. BRS 264 (A), cevada cv. BRS Korbel (B), arroz cv IRGA 409 (C) e braquiária cv. Piatã (D). Blast symptoms caused by the Pyricularia oryzae species on wheat leaves cv. BRS 264 (A), barley cv. BRS Korbel (B), rice cv IRGA 409 (C) and Brachiaria cv. Piatã (D).

Os isolados 16.0.001j, 16.0.003j, 16.0.004j, 16.0.011j e 001 foram mais agressivo em relação ao hospedeiro do arroz (Tabela 2, Figuras 1C), proporcionando médias de 45,88; 45,89; 45,90; 45,91; e 45,89\% respectivamente de área foliar infectada. Com relação aos resultados podemos observar que os isolados de trigo não infectaram o hospedeiro de arroz, isto era previsto pois o Avr1-CO39 é um gene de avirulência do fungo da brusone do trigo e não do arroz (COUCH et al., 2005). De acordo com os autores Maciel et al. (2014) o gene de avirulência Avr1-CO39 foi detectado em 98\% das amostras de trigo (com as únicas exceções em SP). Isto foi confirmada em teste de patogenicidade cruzada, aonde todos os isolados obtidos de trigo foram avirulentos na cultivar de arroz Marateli. 
Com relação aos isolados 16.0.003j, 16.0.011j; 16.0.013j, 16.1.003j, 16.1.009j, 16.1.011j e 16.1.015j foram os mais agressivos à braquiária (Tabela 2, Figura 1D), com médias de 47,67; 47,69; 47,68;47,68;47,69;47,67 e 47,69\% de área foliar infectada. Um dos fatores que explicaria a maior agressividade desses isolados em braquiária é a origem de alguns isolados do próprio hospedeiro, podendo assim, apresentar melhor adaptabilidade.

Finalmente, este estudo demonstrou também, que $P$. oryzae patótipo Triticum tem uma gama de hospedeiros mais ampla do que trigo, arroz, cevada, (GOULART et al., 2007; REGES et al.,2016). Levando em consideração a gama de hospedeiros, podemos destacar a importância das plantas invasoras em áreas de trigo como fonte de inóculo inicial do patógeno. A espécie de Urochloa spp. além de ser a forrageira mais cultivada no país, é um potencial fonte permanente de inóculo inicial entre as épocas de cultivo de trigo, mantendo ativo o inóculo de P. oryzae patótipo Triticum (REGES et al., 2016).

\section{CONCLUSÃO}

De acordo com os resultados, conclui-se que os isolados de Pyricularia oryzae testados, foram patogênicas à trigo, cevada, arroz e braquiária, com diferenças na agressividade.

\section{AGRADECIMENTOS}

Á Universidade Estadual Goiás (UEG) pela aprovação do projeto de pesquisa. A Empresa Brasileira de Pesquisa Agropecuária de Trigo (EMBRAPA) e o IRGA (Instituto Rio Grandense do Arroz) pelas concessões das sementes que foram utilizadas no experimento.

\section{REFERÊNCIAS BIBLIOGRÁFICAS}

ANJOS, J. R. N.; SILVA, D. B.; CHARCHAR, M. J. D'A.; RODRIGUES, G. C. Ocorrência de brusone (Pyricularia grisea) em trigo e centeio na região dos cerrados do Brasil central. Pesquisa Agropecuária Brasileira, Brasília, v. 31, n. 1, p.79-82, 1996.

BAILEY, A. G.; EIJNATTEN, C. V. Corn gray spot caused by Pyricularia grisea. Phytopathology, St. Paul, v. 51, n. 2, p.197-198, 1961.

CASTROAGUdín, V. L., CERESINI, P. C, OLIVEIRA, S. C., REGES, J. T. A., MACIEL, J. L. N., BONATO, A. L. V., DORIGAN, A. F., MCDONALD, B. A. Resistance to QoI fungicides Is widespread in Brazilian populations of the wheat blast pathogen Magnaporthe oryzae. Phytopathology, St. Paul, v. 105, n. 3, p.284-294, 2015.

COUCH, B. C., FUDAL, I., LEBRUN, M.-H., THARREAU, D., VALENT, B., VAN KIM, P.,NOTTEGHEM, J.-L., KOHN, L. M. Origins of host-specific populations of the blast pathogen Magnaporthe oryzae in crop domestication with subsequent expansion of pandemic clones on rice and weeds of rice. Genetics, Bethesda, v. 170, n. 2, p.613-630, 2005.

$\mathrm{COUCH}$, B. C., KOHN, L. M. A multilocus gene genealogy concordant with host preference indicates segregation of a new species, Magnaporthe oryzae, from M. grisea. Mycologia, New York, v. 94, n. 4, p.683-693, 2002. 
CRUZ, M. F.; PRESTES, A. M.; MACIEL, J. L. N.; SCHEEREN, P. L. Resistência parcial à brusone de genótipos de trigo comum e sintético nos estádios de planta jovem e de planta adulta. Tropical Plant Pathology, Brasília, v. 35, n. 1, p.24-31, 2010.

DUVEILLER, E.; HODSON, D.; TIEDMANN, A. Wheat blast caused by Magnaporthe grisea: a reality and new challenge for wheat research. In: INTERNATIONAL WHEAT CONFERENCE, 8, 2010, St. Petersburg. Conference... St. Petersburg: Vavilov Research Institute of Plant Industry, 2010. p. 247-248.

GOUlART, A. C. P.; AMABILI, R. F.; NASSER, L. C. B., FREITAS, M. A. Detecção de Pyricularia grisea em sementes de cevada produzidas em sistema irrigado por pivô central no Cerrado Brasileiro. Fitopatologia Brasileira, Brasília, v. 28, n. 5, p.565-565, 2003.

GOULART, A. C. P.; SOUSA, P. G.; URASHIMA, A. S. Danos em trigo causados pela infecção de Pyricularia grisea. Summa Phytopathologica, Botucatu, v. 33, n. 4, p.358-363, 2007.

IGARASHI, S., UTIAMADA, C. M., IGARASHI, L. C., KAZUMA, A. H., LOPES, R. S. Pyricularia em trigo. 1. Ocorrência de Pyricularia sp. no estado do Paraná. Fitopatologia Brasileira, Brasília, DF, v. 11, n. 3, p. 351-352, 1986.

IGARASHI, S. Análise da ocorrência de brusone do trigo no Paraná. In: RENAPET REUNIÃO NACIONAL DE PESQUISA DE TRIGO, 15, 1988, Passo Fundo. Anais... Passo Fundo: CNPT/EMBRAPA, 1988. p. 1-19.

MACIEL, J. L. N.; CERESINI, P. C.; CASTROAGUDIN, V. L.; ZALA, M.; KEMA, G. H. J.; MCDONALD, B. A. Population structure and pathotype diversity of the wheat blast pathogen Magnaporthe oryzae 25 years after its emergence in Brazil. Phytopathology, St.Paul, v. 104, n. 1, p.95-107, 2014.

MARCHI, C. E.; FERNANDES, C. D.; JERBA, V. F.; BORGES, M. F.; LORENZETTI, E. R.. Brachiaria brizantha: novo hospedeiro de Magnaporthe grisea. Pasturas Tropicales, Colombia, v. 27, n. 2, p.52-54, 2005.

MARANGONI, M. S.; NUNES, M. P., FONSECA JÚNIOR, N.; MEHTA, Y. R. Pyricularia blast on white oats: a new threat to wheat cultivation. Tropical Plant Pathology, Brasília, v. 38, n. 3, p.198-202, 2013.

OU, S. H. Blast. In: OU, S. H. (Ed.). Rice diseases. 2. ed. Wallingford: CAB International, 1985. p. 109-201.

REGES, J. T. A. Biologia e estrutura genética de populações do patógeno da brusone do trigo no Centro-Sul do Brasil. 2016. 76 f. Tese (Doutorado em Agronomia: Sistema de Produção) - Faculdade de Engenharia, Universidade Estadual Paulista, Ilha Solteira, 2016.

REGES, J. T. A.; NEGRISOLI, M. M.; DORIGAN, A. F.; CASTROAGUdÍN, V. L.; MACIEL, J. L. N.; CERESINI, P. C. Pyricularia pennisetigena and P. zingibericola from invasive grasses infect signal grass, barley and wheat. Pesquisa Agropecuária Tropical, Goiânia, v. 46, n. 2, p.206-214, 2016. 
SILVA, F. A. S.; AZEVEDO, C. A. V. The Assistat Software Version 7.7 and its use in the analysis of experimental African Journal of Agricultural Research, Porto, v. 11, n. 39, p.3733-3740, 2016. Disponível em: <https://academicjournals.org/journal/AJAR/article-fulltext-pdf/5E8596460818>. Acesso em: 12 jun. 2017.

URASHIMA, A. S.; IGARASHI, S.; KATO, H. Host range, mating type, and fertility of Pyricularia grisea from wheat in Brazil. Plant disease, St. Paul, v. 77, n. 12, p.1211-1216, 1993. 